\title{
COMPAÑIAS TEATRALES EN AREQUIPA EN 1621 Y 1636
}

- Los dos contratos ${ }^{1}$ abajo reproducidos contienen informes que merecen divulgarse por las luces que arrojan acerca del personal de dos compañías teatrales organizadas en Arequipa, importante población del virreinato del Perú, en la primera mitad del siglo xvir. Como son tan escasas las noticias relativas a las actividades teatrales de las provincias del Sur del Perú y de Bolivia o Alto Perú, estos documentos constituyen una novedad de importancia para la historia cultural de Sudamérica, pues ponen de manifiesto el gran interés que las representaciones dramáticas suscitaban en el público de las colonias de España. Parece improbable que éstas fuesen las primeras agrupaciones permanentes de auténticos actores profesionales que trabajaron en Arequipa ${ }^{2}$, ya que esta ciudad quedaba cerca del camino más frecuentado para ir a las poblaciones del Alto Perú, entre ellas Potosí, rico asiento minero. Además, las escrituras suministran algunos interesantes pormenores sobre el régimen interno de los grupos de actores de aquellos tiempos: estipulan la remuneración de cada actor; indican que la temporada histriónica expiraba en Carnaval, y prueban que un insospechado número de actores, bastante célebres a veces, pasaban de la Península a las Indias. Nuestros documentos, dicho sea de paso, ofrecen nuevos datos para la biografía de esos cómicos peninsulares.

$\mathrm{El}_{4}$ de junio de 1621 comparecieron ante escribano público trece personas, entre actores y actrices, para formar una compañía ambulante; ésta se constituiría por un período de veinte meses (desde el 20 de ese mes hasta el día de Carnestolendas de 1623) y representaría comedias, farsas, entremeses y bailes, no sólo en los teatros

${ }^{1}$ Conservados en el Archivo Notarial de Arequipa, en los tomos corres pondientes a los años 1621 y 1636 , de los escribanos respectivos.-Aprovecho la ocasión para expresar mi más sincero agradecimiento al R. P. fray Víctor M. Barriga, religioso de la Merced, catedrático de la Universidad de San Agustín de Arequipa, erudito historiador y apreciado amigo, por haber tenido la bondad de llamarme la atención sobre estos contratos y haberme proporcionado una fiel copia de los manuscritos.

${ }^{2}$ Las noticias más antiguas de representaciones teatrales en Arequipa se remontan a 1564 , año en que se pusieron en escena, para la fiesta de Corpus, una comedia y tres entremeses. (Véase Gullilimo Lohmann Villena, El arte dramático en Lima durante el virreinato, Madrid, 1945, págs. 19-20). 
públicos, sino también en casas particulares de Chucuito, La Paz, Oruro, Potosí, Chuquisaca y "todas las demás provincias, villas e lugares de este reyno". Componían el elenco las personas siguientes: Manuel de Ribera, "autor de comedias" (esto es, 'director') y su mujer Gabriela de Villalobos, Diego Bernardo de Quirós y su mujer María Suárez, Martín de Ayllón y su mujer Juana de Saucedo, Juan Bautista de Villalobos, hombre de edad avanzada, y su mujer Ana Aguilar, Hernando de Llanos y su mujer Marina del Castillo, Juan de Villalobos, Dionisio y Baltasar de Velasco y Francisco Ortiz ${ }^{3}$. Convenían en no disolver la agrupación durante el tiempo estipulado, imponer a los desertores una multa de mil pesos ensayados

${ }^{3}$ Manuel de Ribera era natural de Lisboa. Contrajo matrimonio en la Nueva España con la actriz Gab riela d e Villalobos, hija de Juan Bautista de Villalobos. Llegó al Perú a fines de 1613 , y en 1614 él y su mujer se sumaron al grupo de Gabriel del Río. Al año siguiente organizó una nueva compañía, cuyo verdadero director fué su suegro Juan Bautista de Villalobos. El matrimonio Ribera firmó un contrato para bailar en Lima en 1620; a fines de este año salía con su grupo, recién formado, para las provincias de la Sierra. En ${ }_{1625}$ la compañia, dirigida por Ribera, actuaba en Oruro. Su compañía "de partes" salió de Lima con rumbo a las provincias del Sur en 1628 . En 1633 se encargó Ribera de la habitual representación sacra en la capital del virreinato. En ${ }_{16}{ }_{34}$ dirigía una casa de juego de pelota. (Lohmann Villena, págs. 88, $127,130,142-148,158-160,195,201-202,212,619)$.

En 1613 Diego Bernardo d e Quirós acompañó a Juan Bautista de Villalobos al Perú. Actuó en Lima, en la compañía de Gabriel del Río, durante 1614. Al año siguiente volvió a inscribirse en la de Ribera y Villalobos. En 1619 y 1620 trabajaba para otros empresarios. Se hallaba en Oruro en 1625 . Dos años después, él y su mujer $\mathrm{M}$ a ría $\mathrm{Su}$ áre $\mathrm{z}$ se agruparon con otros actores para ir a la Sierra. En 1638 actuaba bajo la dirección de Francisco Hurtado. (Lohmann Villena, págs. 127, 130, 147, 155, 158, 160, 195, 200, 219 ).

En 1619 Martín de Ayllón se comprometía a bailar, solo o acompañado, en las funciones dadas en Lima por la compañía Guevara-Ávila. Durante la temporada de 1620 , él y su mujer Juana de San Roque se obligaron a trabajar bajo las órdenes de Alonso de Ávila, bailando en los entremeses y comedias, "debiendo ella cantar con guitarra o arpa los tonos que los músicos de la agrupación la dieran y enseñaran”. En 1622 Ayllón bailaba en las comsdias representadas en el Coliseo de Santo Domingo en Lima. A fines de 1622 se inscribió en la compañía de Julián de Iraola, que iba a realizar una jira por el Alto Perú. Trabajaba de nuevo en Lima en 1638 en la compañía de "Los Conformes". En 1652 era miembro de la agrupación organizada con objeto de ir hasta Potosí. Durante la temporada de 1655 recibía un salario de 640 pesos. Actuaba en Lima desde 1657 hasta 1664. (LohmanN Villena, págs. $155,15^{8}, 166-167,169-170,218-219,238,241-242,244,248,25^{2}, 255^{-2} 5^{6}$ ).

Seguramente J u an a d e $\mathrm{S}$ a u c ed o es la misma Juana de San Roque que en 1620 aparece como mujer de Ayllón, y se la describe como bailarina de dieciséis años de edad (Lohmann Villena, págs. $150,155,158$ ).

Juan Batista de Villalobos nació en Sevilla hacia 1566. En 1588 trabajaba en Valencia en la compañía de Rodrigo Osorio; luego se sumó, en 1595, a la agrupación dirigida por Gaspar de Porres para actuar en Madrid. Hacia 1594 estaba en Toledo con Lope de Vega, y en Madrid depuso el 22 
y no permitir que el director despidiera a nadie sin licencia de la compañía ni admitiera nuevos socios sin común acuerdo. El sueldo oscilaba entre cuatro reales de parte (ganados por dos de las mujeres) y diez reales de parte (ganados sólo por Gabriela de Villalobos). Juan Bautista de Villalobos quedaba encargado de proveer el vestuario, asignándosele la suma de cuatro reales de parte. Martín de Ayllón (menor de veinticinco años) y las cinco actrices renunciaban a los derechos conferidos por las leyes especiales a menores y mujeres. Las trece personas obligaban sus personas y sus bienes, presentes y futuros, para la ejecución del contrato. Al parecer, tres

de abril de 1595 en el juicio que contra éste se siguió por las injurias contra el comediante Velásquez y su mujer. Salió de España al Nuevo Mundo después de 1607 . Entre 1608 y 1613 trabajó en México, de donde pasó con su compañía al Perú. En esta compañía estaban su esposa Beatriz Rodríguez, sus hijos Juan, Catalina y Gabriela y su yerno Manuel de Ribera, y además Diego Bernardo de Quirós, Damián de Moya, Francisco de Vega y el mexicano Jusepe de Aspilla. En 1614, Villalobos compró veinticuatro comedias a once pesos cada una, y ofreció representar gratuitamente en Lima (oferta no aceptada) las comedias destinadas a la fiesta de Corpus. Al año siguiente se comprometió a proporcionar los textos de las comedias, cobrando cuatro reales por cada una. El 12 de marzo de 1620 su compañía se dirigió al puerto de Pisco, de donde partiría hacia el interior. Regresó a España en 1621, y al año siguiente se encargó de la construcción y administración del Coliseo de Sevilla. (Lohmann Villena, págs. 127-129, 146-147, 157, 620-621; Cristóbal Pérez Pastor y A. Tomillo, Proceso de Lope de Vega por libelos contra unos cómicos, Madrid, 19o1, págs. 8 y 10; José Sánchez Arjona, Noticias referentes a los anales del teatro en Sevilla, Sevilla, 1898, pág. 218; Hugo Albert Rennert, The Spanish stage in the time of Lope de Vega, New York, 19o9, pág. 63o).

Al parecer, Beatriz Rodríguez había muerto, y Villalobos se habia casado con Ana Aguilar después de ${ }_{1615}$.

He r n a ndo de Ll a nos era natural de Cangas. No contrajo matrimonio con Marina del Castillo hasta el 30 de agosto de 1624 , tres años después de estar en Arequipa. Trabajaba en Lima en 1623 como miembro de la compañía de Antonio de Morales, y antes de terminar la temporada pasó a la de Gabriel del Río. Al año siguiente volvió a actuar bajo las órdenes de Morales, cuya compañía se deshizo en 1626. Poco después se incorporó a la agrupación de María del Castillo, para quien no trabajó mucho, pues en 1627 se alistó para actuar bajo la dirección de Ana Morillo. Fué contratado a fines del mismo año de 1627 para ir a la Sierra por espacio de tres años. Estaba de vuelta en Lima en 1629. (Lohmann Villena, págs. 173, 175-176, 179, 197-200, 203, 615)

Marina del Castillo, llamada por su corta edad "Marinilla", nació en 1610 en Angola. Ya representaba y cantaba en Lima durante la temporada teatral de 1620 . Al año siguiente ella y los otros músicos de la compañía de Alonso de Ávila cantaron la loa y las canciones de la comedia El blasón de los Alvarados. De 1623 en adelante actuaba en las compañías a que pertenecía su marido Hernando de Llanos. En 1629 tomó el hábito de monja. (LohmanN Villena, págs. $157^{-1} 5^{8}, 164^{-165}, 173,175,198,200,610$ ).

Juan de. Villalobos, el Mozo, era hijo de Juan Bautista de Villalobos, y trabajó en las compañías de su padre y de su cuñado Manuel de Ribera. (Lohmann Villena, págs. 127, 190, 147, 201). 
de las mujeres -entre ellas Juana de Saucedo, aunque en su caso no es seguro- y Baltasar de Velasco no sabían escribir, y fué preciso que firmaran testigos en su lugar.

Quince años después, el 22 de agosto de 1636 , comparecían ante escribano público, en Arequipa, siete actores deseosos de formar una agrupación teatral: Juan Bautista de Villalobos, Jerónimo Jiménez, Bartolomé de Morales, Francisco Duarte, Francisco de Prada, Francisco Esteves y Domingo de Sosa ${ }^{4}$. Pensaban representar comedias por un período de tres años, comenzando el día de Carnestolendas de 1637. Se asignaba a Juan Bautista de Villalobos una parte de dieciocho reales, ganada en esta forma: por el trabajo de su mujer una parte de a ocho reales, por el de su hija una parte de a cinco, por las colgaduras y el vestuario que se obligaba a proveer una parte de a cuatro, y por ayudar a proporcionar las comedias una parte de a

De Baltasar de Velasco sabemos que en 1612 ingresó en la compañía de Torres-Burgos-Arriaga. (Lohmann Villena, págs. 122-123).

El músico Francisco Ortiz de A lesanco regresó del Alto Perú a Lima en 1615: era miembro del grupo encabezado por Miguel de Burgos. En 1617 se incorporó a la compañía dirigida por Juan Crisóstomo de Guevara. Perteneció al grupo que en 1620 organizó Manuel de Ribera para ir a las provincias de la Sierra. En 1624 acababa de volver de Potosí a Lima, donde se inscribió en la compañía de Antonio Morales. En el mismo año comenzó a trabajar para los empresarios Alonso de Ávila y Gabriel del Río. En 1628 actuaba en el grupo de Ana Morillo. Al año siguiente salió de Lima para las provincias de arriba. (Lohmann Villena, págs. 148, 150, 159-160, 175-176, 180, 197, 201 , 203).

${ }^{4}$ Por lo visto, el viejo Villalobos (que tenía ya unos ochenta años) había regresado de España; o quizá se trate de su hijo, Ju a n de Villalobos.

Jerónimo Jiméne $z$ y $D$ uarte era natural de Marchena. En 1611 trabajaba en Lima en la agrupación dirigida por Miguel de Burgos. En 1612 organizó su propia compañía, que el día de Corpus y durante su octava representó las comedias La vida de San Bernardo de Alcira y El esclavo del demonio. En la temporada de 1613 actuaba en el grupo encabezado por Gabriel del Río. En $1_{16}{ }_{15}$ se inscribió en la compañía de Manuel de Ribera. Se casó con Inés de Jáuregui el 8 de marzo de 1619 . Juan Bautista de Villalobos lo contrató en 1620. En 1622 Jiménez pertenecía a la agrupación de Antonio Morales. A fines del mismo año él y su mujer se comprometían a realizar una jira por el Alto Perú. En 1627 dirigía en Lima su propia agrupación. Se unió, para actuar en Lima en 16.12, a la compañía de "Los Conformes", cuyo director era su yerno Francisco Hurtado. Al año siguiente trabajaba en "La Compañia Nueva", grupo recién organizado, con Alonso de Haro al frente. En 1640 se hallaba en Quito. (Lohmann Villena, págs. 121, 123-126, 147, 157, 167, 169, 201, 223-228, 614).

Bartolomé de Morales figuraba entre los comediantes de Antonio de Morales, que daban representaciones en Lima durante la temporada de 1623. En 1698 se asoció con otros para representar comedias en los Valles, en las ciudades de Trujillo y Sana, etc. (Lohmann Villena, págs. 173, 219). Quizá fuese el actor que trabajaba en España en 1605 (RENNERT, op. cit. pág. $5^{28)}$. 
un real. Bartolomé de Morales recibiría ocho reales de parte; Francisco Duarte, uno de los dos empesarios, el mismo sueldo; Francisco de Prada, nueve reales; Francisco de Esteves, siete reales; Domingo de Sosa, ocho por su trabajo y diez por el de su mujer; Jerónimo Jiménez, el otro empresario, ganaría ocho reales por su trabajo, otros ocho por el de su hija, seis por el de su mujer, y un real por ayudar a Villalobos a proporcionar las comedias. En total, el grupo se componía de doce personas, siete actores y cinco actrices. Los contratantes se obligaban a viajar a todas partes, menos al Alto Perú, y a no ausentarse de la compañía, so pena de "pagar todos los daños, intereses i menoscabos que por su culpa se causaren a los demás”. Convenían en que se multara al infractor con quinientos pesos. Como en la escritura de 1621, también aquí obligaban todos sus personas y bienes, presentes y futuros, para la ejecución del contrato. Una especie de post-data anula lo convenido acerca del sueldo de Francisco de Prada, quien prefirió cobrar anualmente "seicientos pesos de a ocho reales, pagados lo que sea cada mes porrata de la dicha cantidad del contado".

Francisco Duarte y su hija de diecinueve años, María del Águila, actuaban en 1646 y 1647 en Lima bajo las órdenes de Francisco Hurtado. María del Castillo los contrató a ambos para representar en su corral. El hijo de Francisco Duarte y la hija ya mencionada se inscribieron en 1660 en la agrupación encabezada por Juan Ruiz de Lara. (Lohmann Villena, págs. $232,234,248$ ).

Francisco de Prada pertenecía al grupo de "Los Conformes", que se constituyó en la capital en $165^{2}$, y seguía en él en 1653 . En 1654 cobraba un peśo por cada función Por toda la temporada de 1655 se le asignaban 640 pesos. Se unió a la compañía de Ruiz de Lara en 1657. (Lohmann Villena, págs. $\left.239^{-242}, 244\right)$.

Domingo de Sosa nació en 1604 en Pontevedra. Lo encontramos, como bailarín, en la compañía de Antonio de Morales en 1623 y 1624 . Al año siguiente él y su mujer Juana Francisca Pinzón, bailarina, engrosaron las filas del grupo de Alonso de Ávila y Gabriel del Río. Él representaba y bailaba en 1626 en la compañía de María del Castillo. En 1627 se alistaba para actuar. bajo la dirección de Ana Morillo. En el ãno siguiente continuaba en Lima con el mismo grupo. En 1639 él y su mujer bailaban bajo las órdenes de Francisco Hurtado. Se hallaba en Potosí en 1642. Diez años después actuaba en Lima en el Corral de la calle de San Agustín. Trabajó con "Los Conformes" durante las temporadas de $\cdot 1653$ y 1654 . En 1655 cobraba un sueldo de 640 pesos. Durante 1657 y 1658 trabajaba bajo las órdenes de Ruiz de Lara. (LoHMANN Villena, págs. 173, 175, 179-180, 198-199, 201, 219, 223, 239-242, 244-245 619). 


\section{COMPAÑÍA PARA LA REPRESENTAGIÓN \\ DE COMEDIAS EN LA GIUDAD DE AREQUIPA Y OTRAS DEL VIRREINATO ( I62 I )}

En el nombre de Dios amén. Sepan cuantos esta carta vieren, cómo nos, Manuel de Rivera, autor de comedias, y doña Grabiela de Villalobos, su legítima mujer; y Bernardo de Quiroz y doña María Suárez, su legítima mujer; y Martín de Ayllón y Juana de Saucedo, su legítima mujer; y Juan Bautista de Villalobos y doña Ana Aguilar, su legítima mujer; y Hernando de Llano y Marina de Castillo, su legítima mujer; y Juan de Villalobos, Dionicio y Baltazar de Velasco y Francisco Ortiz y otros representantes y residentes en esta ciudad de Arequipa, del Perú, con licencia que nos, las dichas doña Grabiela de Villalobos y doña María Suárez, doña Juana de Saucedo, doña Marina de Castillo y doña Ana de Aguilar, pedimos y demandamos a los dichos Manuel de Rivera, Bernardo de Quiroz, Martín de Ayllón, Hernando de Llano y Juan Bautista de Villalobos, nuestros maridos, para otorgar esta escritura e todo lo en ella contenido, la cual nos los susodichos concedemos, damos i otorgamos a las dichas nuestras mujeres para hacer esta escriptura y nos las susodichas la aceptamos y recibimos, y usándo de ella todos juntos los susodichos de mancomún y por lo que a cada uno de nosotros toca, otorgamos e concedemos, por esta presente carta, que hacemos compañía indivisible, y que no se pueda dividir por ninguno de nosotros, si no es por muerte e enfermedad grave e caso fortuito e inopinado, o por lo que adelante de esta escriptura se declara, para representar todos juntos en esta ciudad de Arequipa, la de Chucuito, La Paz, Oruro, Potosí, Chuquisaca y todas las demás provincias, villas e lugares de este reyno: comedias, bailes, farsas y entremeses en teatros públicos y casas particulares y en las demás partes que se ofrecieren, como los tenemos de suso acostumbrado desde veinte días de este presente mes de Junio de mil seiscientos y veintiún años hasta el día de Carnestolendas del año de mil y seiscientos y veinte y tres, que serán veinte meses, poco más o menos, la cual dicha compañía hacemos con las dichas condiciones y grabámenes siguientes:

Primeramente que por ninguna compañía sin caudillo puede ser bien dirigida i gobernada, elegimos e nombramos por nuestro caudillo y autor de esta compañía a el dicho autor Manuel de Rivera, al cual seguiremos $\mathrm{y}$ obedeceremos en todo lo que señalare y se ofreciese en las representaciones de los papeles y facines $^{5}$ de la representación en sus actos de comedias, farsas, bailes, entremeses.

Item es condición que ninguno de nosotros de su parecer tenga libertad para salirse de la dicha compañía, en el dicho tiempo, sino que ha de asistir en ella y su representación, pena de un mil pesos ensayados en cualquier de nosotros; nos damos por condenados, luego que lo tal hiciere, los cuales pagaremos al Santo Oficio de la Inquisición destos reynos. Damos poder a los señores inquisidores y cualquier de sus ministros, a quienes nos obligamos en forma por la dicha cantidad para que las

${ }^{5}$ facines $=$ 'faquines'. 
cobren de nosotros y de nuestros bienes, como deuda líquida cierta, la cual hacemos desde agora para cuando contraviniéramos a lo susodicho, y el día que cualquiera de nosotros se despidiere de la dicha compañía y .demos libertad, le señalaremos por término y por plazo para que en él se cumpla y désta decida y que, luego que lo tal lo sepa, el dicho Tribunal de la Inquisición y cualquiera de sus ministros puedan ejecutar a cualquier de nosotros, que lo tal lo hiciere, por los dichos un mil pesos ensayados, los cuales haya y tome para sí el dicho Tribunal de la Inquisición como cosa suya que se les damos y obligamos a pagar por pena, qué si faltáremos a esta condición y por la ocupación que ha de tener la persona que los cobrase.

Item es condición que yo el dicho Manuel Rivera, autor, no he de poder despedir de mi libre voluntad a ninguna de la dicha compañía, sin parecer i acuerdo de ella, de manera que el que se despide sea con licencia de la compañía, la cual ha de dar por escrito, pena que si de otra manera el dicho autor despidiere alguna de la dicha compañía, incurra en los dichos mil pesos ensayados, según dicho es, y el que se despidiere con licencia de la compañía, según está declarado, no ha de incurrir en pena alguna.

Item es condición que todas las veces que el dicho autor quisiere, con parecer de la dicha compañía, recibir alguna persona o personas más de las que en ella estamos convenidos, puede recibirla con acuerdo y parecer de todos y señalar el salario e parte que le pareciere, a lo cual se ha de obligar toda la compañía. Con las cuales dichas condiciones hacemos e instituímos la dicha compañía.

Lo que Dios fuere servido que ganemos en ella, lo hemos de partir entre nosotros hermanablemente, sin hacer agravio a nadie, y cada uno ha de llevar la parte siguiente: el dicho Manuel de Rivera, autor, ha de haber y llevar y se le han de pagar nueve reales de parte; la dicha doña Grabiela de Villalobos, su mujer, ha de llevar diez reales de parte; el dicho Bernardo de Quiroz ha de llevar nueve reales de parte; la dicha María Suárez, su legítima mujer, ha de llevar ocho reales de parte; el dicho Martín de Ayllón ha de llevar ocho reales de parte; la dicha Juana de Saucedo, su mujer, ha de llevar nueve reales de parte; el dicho Hernando de Llano ha de llevar siete reales de parte; la dicha Marina de Castillo, su mujer, ha de llevar cuatro reales; el dicho Juan Bautista de Villalobos por la ropa de la comedia, dando lo necesario, ha de llevar cuatro reales de parte; la dicha doña Ana de Aguilar, su mujer, ha de llevar cuatro reales de parte; el dicho Juan de Villalobos, el Mozo, ha de llevar nueve reales de parte; el dicho Baltazar de Velasco ha de llevar siete reales de parte; el dicho Francisco Ortiz ha de llevar ocho reales de parte.

La dicha repartición se ha de hacer entre nosotros de todos los pesos que durante el dicho tiempo ganáremos en las dichas comedias, dando a cada uno su parte, según y como está declarado y de la manera y a los tiempos que tenemos de costumbre hacer la dicha repartición en la dicha compañía; y, pasando el dicho día de Carnestolendas del año de seiscientos veinte y tres, la dicha compañía ha de quedar deshecha por lo 
contenido en esta escriptura y cada uno de nosotros en su libertad, sin obligación de cosa alguna de lo en ella contenido.

$\mathrm{E}$ yo el dicho Martín de Ayllón, por ser menor de veinticinco años y mayor de diesciocho, juro a Dios y a la cruz que hago con los dedos de. mi mano derecha que no iré ni vendré contra esta escritura, por razón de mi menor edad ni por otra causa que me competa de fuero ni de derecho y, si alguna me pueda aprovechar, en este caso expresamente desde luego la renuncio i me obligo a seguir la dicha compañía en el dicho tiempo.

E nos, las dichas doña Grabiela de Villalobos y doña María Suárez, Juana de Saucedo, Marina de Castillo y doña Ana de Aguilar, por ser mujeres, renunciamos el beneficio del Beleyano e ley de partida y la nueva Constitución y leyes de Toro ${ }^{6}$, que son y hablan en favor y ayuda de las mujeres que se obligan, para que no nos valgan ni puedan valer agora ni en ningún tiempo en juicio ni fuera de él, por cuanto de ellas fuimos avisadas de en una en una por el presente escribano y de su efecto y a lo que nos obligamos y quedamos obligadas en esta escriptura, y particularmente para si alguna de nosotras se saliese de la dicha compañía antes del dicho día de Carnestolendas de mil seiscientos y veintitrés, o incurriese en la pena de mil pesos ensayados al Santo Oficio de la Inquisición deste reyno e cualquier ministro suyo, luego que nos salgamos de la dicha compañía antes del dicho tiempo o sin licencia del dicho Manuel de Rivera, autor, e de los demás o por enfermedad grave o caso fortuito que nos lo estorve. $Y$ para mayor fuerza i vacilación desta escriptura, nos, las dichas Grabiela de Villalobos, doña María Suárez, doña Juana de Saucedo, doña Ana de Aguilar y Marina de Castillo, cada una de por sí, juramos por Dios Nuestro Señor y por las páginas de los Santos Evangelios y por la señal de la cruz que cada una de nosotras hace con su mano derecha que entendemos bien el efecto de esta escriptura, porque, demás de saberlo, nos fué dado de saberlo y entenderlo por el presente escribano, y que ninguna de nosotras no tenemos hecho ni haremos juramento ni reclamación, y que, al tiempo de nuestros matrimonios, ni juramos ni prometimos ni juraremos ni prometeremos de ir contra esta escriptura ni parte de ella ni por la paga de los dichos un mil pesos ensayados. Si incurriéremos en la pena, nos hemos protestado

- El Beleyano es el senadoconsulto Veleyano, que prohibía a las mujeres el obligarse como fiadoras por persona alguna (Alexand. Scoti et Jo. GotT. Herneccir, Vocabularium juris utriusque, Bousquetiana 1759 , vol. III, pág. 516; Elías Zerolo, Diccionario enciclopédico de la lengua castellana, nueva ed., París, s. f., vol. II, pág. 984).-Con la ley de partida se alude, naturalmente, a las Partidas de Alfonso el Sabio.-La nueva constitución es la Nueva recopilación, realizada por Bartolomé de Arrieta y promulgadá por Felipe II en ${ }_{15} 67$ (cf. Rafael Altamira, Historia de España y de la civilización española, $3^{\mathbf{a}}$ ed., Barcelona, 1919 , vol. III, págs. 328-331).-Las leyes de Toro, acordadas en las Cortes de Toledo en 1502 , se publicaron en 1505 . Con las ochenta y tres leyes de esta compilación se realizó la reforma legal del derecho privado. "En punto a la mujer casada, dice Altamira (op. cit., vol. II, págs. 441-443), se fija minuciosamente su falta de personalidad jurídica, dependiendo de la licencia del marido en casi todos sus actos". 
de no enagenar ni consentir que se enagenen nuestros bienes por tales y parafernales i gananciales, y pareciese lo contrario, nos relebamos y en ningún tiempo iremos ni bendremos ni reclamaremos de lo que está dicho, ni de parte de ello, por razón de nuestras excepciones, porque todas con nuestros derechos las renunciamos, y no alegaremos que, para otorgar esta escriptura, fuimos apremiadas y atraídas o inducidas, sino que, de nuestra voluntad, y porque nos está bien y es probecho nuestro y en ello no somos engañadas, antes es nuestro útil entrar en la dicha compañia, por la cual no pediremos absolución ni relaxación deste juramento, aunque sea por efecto de ser i dar en juicio y aunque nos la pidiesen nos conceda a todas juntas e cada una por sí, no usaremos de la tal conseción y si aprovecharnos y valernos, quisiéramos della, de la que nosotras tal hiciere, sea tenida por perjura y tantas cuantas veces nos fuere concedida la dicha absolución o relajación, tantas de nuevo tornamos a hazer del dicho juramento y en la conclusión dél, cada una de nosotras dixo: sí juro i amén.

$\mathrm{Y}$ todos los dichos trece otorgantes de suso mencionados, cada uno por lo que le toca para el cumplimiento, firmeza y para lo que dicho en esta escriptura, obligamos nuestras personas y bienes avidos y por haber, damos poder cumplido a todas y cualesquier justicias del rey nuestro señor de cualesquier fuero e jurisdicción que sean, y, en particular, a las del Santo Oficio de la Inquisición, para que si incurriésemos en la dicha pena, los cuales nos apremien a ello por todo rigor de derecho como por sentencia de juez competente pasada en cosa juzgada y renunciamos la ley sit convenerit de jurisditione omnium judicum y todas las demás de nuestro favor y la que dize que general renunciación de leyes fecha non vala, en testimonio de la cual otorgamos ante el presente escribano y testigos, que es fecha en la ciudad de Arequipa del Perú, en cuatro dias del mes de Junio de mil seicientos veinte y un años. Y los dichos otorgantes que yo el dicho escribano que doy le que conozco, lo firmaron los dichos Manuel de Rivera, Grabiela de Villalobos, Bernardo de Quiroz, Martín Ayllón, Hernando de Llano; Juan Bautista de Villalobos y Juan de Villalobos y Baltazar de Velasco y Francisco de Ortiz y Juana de Saucedo. Y por la dicha doña Marina del Suárez y Marina de Castillo, que dijeron que no sabían escribir, lo firmó por cada testigo: Don Antonio de Paredes, Juan Camacho y Pedro Romero de Córdova presentes (firmado).

Manuel de Rivera, Grabiela de Villalobos, Bernardo de Quiroz. Por testigo de doña María Suárez, Juan Camacho. Martín de Ayllón. Hernando de Llano. Juana de Saucedo, a ruego y por testigo Antonio Paredes. Juan Bautista de Villalobos. Baltazar de Velasco, Juan Camacho como testigo. Francisco Ortiz. Juan de Villalobos.

Ante mí, Pedro Ibáñez de Irruegas, Escribano Público.

\section{COMPAÑIA PARA LA REPRESENTACIÓN DE COMEDIAS ORGANIZADA EN AREQUIPA ENTRE JUAN BAUTISTA DE VILLALOBOS Y OTROS $\left(163^{6}\right)$}

En el nombre de Dios amén. Sepan cuantos esta carta vieren cómo en la ciudad de Arequipa, en veintidós días del mes de Agosto de mil y 
seiscientos y treinta y seis años, ante mí, el escribano y testigos parecieron don Juan Bautista de Villalobos y Gerónimo Jiménez y Bartolomé de Morales y Francisco Duarte y Francisco de Prada y Francisco Esteves y Domingo de Sosa, representantes y residentes en esta ciudad, que yo, el escribano, doy fe, que conozco a los otorgantes que son convenidos y concertados en esta manera, que se obligan unos a otros de asistir y estar juntos de compañia para representar comedias por tiempo i espacio de tres años que an de correr y comenzar a contar desde el día de Carnestolendas venidero del año que viene, de mil sëiscientos y treinta y siete en adelante. Y a de gozar el dicho Juan Bautista de Villalobos, por lo que su mujer y hija representaren, una parte de a ocho reales por el trabajo de su mujer y cinco reales de parte por la de su hija, y por las colgaduras y demás ropa necesaria, tocante al vestuario, a de ganar cuatro reales de parte este tiempo. Y el dicho Bartolomé de Morales a de ganar por el trabajo de su persona una parte de a ocho reales; i el dicho Francisco Duarte a de ganar otra parte de a ocho reales; y el dicho Francisco de Prada a de ganar una parte de a nueve reales; y el dicho Francisco de Esteves a de ganar una parte de siete reales; y el dicho Domingo de Sosa a de ganar por su persona una parte de a ocho reales y por su mujer diez reales de parte; y el dicho Gerónimo Jiménez a de ganar una parte de a ocho reales y por la de su hija una parte de a ocho reales y por su mujer seis reales de parte. Y más han de sacar dos reales de parte por las comedias, las cuales se han de repartir entre los dichos Gerónimo Jiménez y el dicho Juan Bautista de Villalobos, y esta compañía hacen con las calidades y condiciones siguientes:

Primeramente es condición de que cada uno dellos a su costa durante el dicho tiempo de los tres años han de estar abaiados ${ }^{7}$ y prevenidos para hacer viaje a cualquier parte, como no sea para Oruro, Potosí u otras partes de la tierra de Arriba, y han de ir por las partes que por el dicho Gerónimo Jiménez y Francisco Duarte fueran señaladas. Y a todos los referidos y cada uno de ellos, se obligan a pagar todos los daños, intereses i menoscabos que por su culpa se causaren a los demás, cuya prueba queda deferida en el simple juramento de los dichos Gerónimo Jiménez y Francisco Duarte, sin que sea necesaria otra prueba ni averiguación alguna, porque de ella se releban y quedan relevados.

Iten es condición que, si alguno o algunos se ausentaren de la dicha compañía o no quisieran seguirla a cualquier parte que vaya, fuera de los susodichos, luego que lo tal suceda, cada uno de los que incurriera en lo referido so pena de pena convencional de quinientos pesos corrientes a ocho reales que pagará cualquiera que hiciere la dicha falta o no quisiere seguir la dicha compañía, que desde luego aplican para los gastos del Tribunal de la Inquisición, en que desde luego se dan por perdonados el que contraviniere a lo referido como no sea por enfermedad que inpida hacer el dicho viaje, lo cual ha de constar por juramento de médico $\mathrm{i}$, siendo por razón de la dicha enfermedad con la calidad dicha, queda relevado de la dicha pena, lo cual con dicha pena pagada o no, o graciosamente le sea remitida esta cuenta, se guarde e cumple y ejecute según y como en ella se contiene, a cuya seguridad y cumplimiento los

\footnotetext{
'abaiado = 'aballado'.
} 
susodichos y cada uno de ellos por lo que le toca obligaron su persona y bienes habidos y por haber y, para su ejecución, dieron poder cumplido a los jueces de su magestad de cualesquier partes que sean y al fuero y jurisdicción de las cuales y cada una se sometieron y renunciaron el suyo propio, jurisdicción, domicilio y vecindad y la ley sit convenerit de jurisditione omnium judicum, para que a ello nos conpelan y apremien como pro sentencia pasada en autoridad de cosa juzgada sobre que renunciaron todas las leyes, fueros i derechos a su favor y la ley que lo prohibe, y lo firmaron de sus nombres, siendo testigos Pedro Suárez de Tórrez, Miguel de Cámara y Diego de Torres presentes. Juan Bautista de Villalobos. Gerónimo Jiménez. Francisco Duarte. Domingo de Sosa Troncoso. Francisco de Prada. Francisco Esteves, Bartolomé Morales.

Ante mí, Diego de Silva, Escribano Público.

Sepan cuantos esta carta vieran cómo nos, Gerónimo Jiménez y Francisco Duarte, residentes en esta ciudad de Arequipa, autores de comedias, decimos que por cuanto tenemos celebrada una compañía para representar comedias tiempo de tres años, que han de correr i contarse desde Carnestolendas del año que viene, de mil y seiscientos y treinta y siete años, y los siguientes representantes que están asentados en la dicha escritura y tienen obligación de representar los dichos tres años, el uno Francisco de Prada, que está presente, a quien le toca y pertenece de los pesos que se recogieren por cada representación que hiciere una parte de nueve reales, y agora estamos convenidos e concertados con el susodicho de que el susodicho deje la dicha parte para nos, conque le paguemos en cada un año seicientos pesos de a ocho reales, pagados lo que sea cada mes porrata de la dicha cantidad del contado, de que el susodicho nos haga suelta para nos de la dicha parte de nueve reales, y de que se haya de obligar a representar los dichos tres años y asistir en la dicha compañía y tomar parte de lo que se representaren, y de lo no hacer así, pague todos los daños e menoscabos que a nos y a la dicha compañía se recrecieren, cuya prueba a de quedar deferida en nuestro juramento.

Y cumpliendo con lo que a nos toca, conforme a la relación de esta escriptura, e otorgamos e conocemos por esta presente carta que, por razón del que el dicho Francisco de Prada a de representar en la dicha nuestra compañía tiempo de tres años que han de correr desde las Carnestolendas del año que viene, de mil y seiscientos y treinta y siete años, nos obligamos de le dar e pagar de cada un año estos dichos seiscientos pesos de a ocho reales cada mes adelantados, lo que montare porratada la dicha cantidad y con la parte de nuebe reales que le tocaba llevar por la presentación de cada comedia, quede para nos. Por cuya causa nos obligamos en la dicha cantidad de seicientos pesos de ellos de cada un año; a mayor abundamiento, nos damos a entregados a toda nuestra voluntad y, cuanto al recibo que no parece del presente, renunciamos la excepción de la pecunia, leyes del entrego e recibo e demás de este caso, como en ella se contiene, y la paga de todos nos los susodichos nos obligamos a la hacer, como vá referido, cada mes porratado llanamente y sin perjuicio alguno, con las costas de la cobranza, que no pagadas en la parte e lugar donde fuéremos llevados o a otras que se nos pidan y de- 
manden, nuestros bienes fueran hallados quien somos presentes o ausentes.

E yo el dicho Francisco de Prada, que presente ha sido, el otorgamiento de esta escriptura, declarando como declaro ser cierto y verdadero todo lo que en ella se contiene y, en conformidad de lo que en ella contenido, otorgo por esta carta y me obligo de representar en la dicha compañía tiempo de tres años que han de correr desde Carnestolendas del año que viene, de mil e seicientos y treinta y siete, sin hacer falta ni me despedir $\mathrm{e}$ ir a las partes e lugares donde me ordenarèn, y solicitar e estudiar y representar los papeles que se me dieren y representarlos por razón de los seicientos pesos en cada un año, con los cuales dejo para Gerónimo Jiménez y Francisco Duarte la parte de nueve reales que me tocaba de la representación de las dichas comedias, para que los cobren y tomen por sí, porque con los dichos seicientos pesos en cada un año me contento y satisfago por mi trabajo y ocupación y, en las que yo no cumpla con el tenor de esta escriptura, me obligo a pagar a dichos Gerónimo Jiménez y Francisco Duarte y a los demás de la dicha compañía todos los daños $\mathrm{e}$ intereses que se les siguieren y recresieren, cuya prueba dejo deferida en el juramento de los susodichos, sin que sea necesario otra prueba que de derecho se requiera, porque de ella le relebo, y para la firmeza y cumplimiento de lo que dicho es, todos tres otorgantes por sí y por cada uno de lo que nos toca, obligamos nuestras personas e bienes avidos $\mathrm{e}$ por haber e damos poder cumplido a cualesquier jueces y justicia de su magestad, y de cualesquier partes que fueren, a las cuales nos obligamos y sometemos e renunciamos el nuestro propio domicilio y vecindad y la ley sit convenerit de jurisditione omnium judicum, para que, a lo que dicho es, nos compelan y apremien, como por sentencia definitiva de juez competente, pasada en cosa juzgada, renunciando a todas las leyes de nuestro favor y la ley general que lo prohibe.

Fecha la carta en esta ciudad de Arequipa, en veinte y dos días del mes de Agosto de mil e seicientos y treinta y seis años, y los otorgantes lo firmaron de sus nombres, a quienes yo, el escribano, doy fe, conozco, siendo testigos Bartolomé Morales, Domingo de Sosa y Francisco Esteves, presentes.

Gerónimo Jiménez. Francisco Duarte. Francisco de Prada.

Ante mí, Diego de Silva, Escribano Público.

Indiana University.

HARVEY L. JOHNSON 